\title{
The Service Quality Evaluation System of Green Agricultural Products in Online Shopping Based on Fuzzy Analytic Hierarchical Method
}

\author{
WANG Shunshan \\ Nanjing University of Finance and Economics \\ Nanjing, China. \\ wss.066@163.com
}

\author{
ZHANG Min \\ Nanjing University of Finance and Economics \\ Nanjing, China
}

\begin{abstract}
With the rapid development of agricultural products e-commerce, shopping green products online has a very broad application prospects and growth potential. As a network service process, it is necessary for buyers and sellers to evaluate and analyze the service quality of buying green products online. On the basis of literature analysis, we construct the servicing evaluation index system of shopping green agricultural products online, adopt index weight evaluation through analyzing many experts and form the relevant dimension series of weights set by using fuzzy Delphi method. As the result, we get comprehensive fuzzy scores and the improving method for the service quality evaluation of buying green products online. Related research conclusions could be able to provide buyers and sellers with reference and basis for decision-making when they buy green agricultural products online, and promote the healthy development of shopping green farm products online through better regulation of trading behavior in the network transaction.
\end{abstract}

Keywords-green agricultural products; online shopping; service quality; evaluation; fuzzy analytic hierarchical method

\section{INTRODUCTION}

Compared with agricultural wholesale in the network transactions, the consuming subjects of shopping green agricultural products online are urban consumers paying more attention to product quality, brand awareness and consumption process satisfaction, rather than the price and quantity. Therefore, shopping green agricultural products online is essentially a network service process. However, because of the service characteristics of simultaneity, heterogeneity, intangibility and perish ability, on the one hand it is difficult to evaluate and compare the service quality of online shopping of green agricultural products. On the other hand, it increases the uncertainty of the consumer purchase behavior decision and the website service management decision, so to a certain extent, hinders the positive development of shopping green agricultural online. This paper is therefore aim to construct the evaluation index system of online shopping service quality of green agricultural products, and evaluate the weight using the fuzzy hierarchy analytic process to provide decision-making reference and basis for contracting parties purchasing green agricultural online. As a result, we expect to promote the healthy development of online shopping of green agricultural products through the normalized behavior.

\section{THE RELEVANT LITERATURE REVIEWS}

\section{A. Theoretical Background Analysis}

Because of the obvious information asymmetry features, online shopping exists a large uncertainty and risk. So how to improve the quality of online shopping services which can increase consumers' trust becomes the emphasis focus of domestic and foreign theoretical research. For example, Alam etc. found the internet word-of-mouse, online shopping experience, expected risk, product reputation and information sources determine the trust perception when consumers purchase online, and directly affect purchase behavior decision-making ${ }^{[1]}$. What is more on the aspect of online shopping of agricultural products, through the case study of two agricultural e-commerce companies in China and USA, Zhao Ping etc. found accurate service positioning, reasonable processing and distribution process, more information sharing and service brand building are the keys to ensure the quality of online shopping service of agricultural products. They deemed that the point of the e-commerce of agricultural products should be placed on the two aspects of increasing farmers income and servicing consumers, and ultimately establish a closed-loop operation from the production, procurement, transaction to the distribution ${ }^{[2]}$. Liang Wenzhuo etc. through the analysis of the consumer preferences of online shopping found that low storage environment requirements, long consumption time, without special demand of logistics packaging, low level of consuming risk of agricultural products will become the main body of agricultural products in network transaction. At the same time, due to the characteristics of agricultural products and restrictions on logistics conditions, online purchase of agricultural products is not only limited in the type chosen, but also difficult to guarantee the quality. Therefore, increased consuming risk results in the difficulty to establish agricultural brand of online shopping ${ }^{[3]}$; Che Yin pointed out that our country network marketing of agricultural products is still at the initial stage existing many issues such as the weak construction of information network, the imperfect network marketing service system, the imperfect network marketing mode, the low degree of standardization of agricultural products, the backward logistics and distribution, the lack of relevant legal norms and the lack of security. We should establish and improve agricultural network marketing service system and its collaborative service mechanism, including of the production 
platform, organization platform, market platform and information platform to enhance the quality of services to promote the healthy development of China's agricultural network marketing ${ }^{[4]}$.

\section{B. The Elements Analysis of Evaluating Online Shopping Service Quality}

It can be seen from comprehensive literature, compared with the evaluation of online shopping service quality, there is little research on the evaluation of online shopping service quality of agricultural products (especially green agricultural products), a fully targeted evaluation scale or evaluation system has not yet been retrieved. Therefore, this study aims to build a set of service quality evaluation index system which concerns the green agricultural products online shopping consumers as the study object, in line with the actual situation of China's e-commerce and network marketing.

\section{The Model of Multi FuZzy AnAlytic Hierarchy}

\section{A. The Construction of the Model}

We first conducted a service quality evaluation of green agricultural products online shopping of the selection of entries, for which we prepared a set of open questionnaires, including the following questions: (1) how do you evaluate the online shopping behavior of green agricultural products? (On the purchase of varieties, quantity, price and quality, etc.) (2) how about the situation when you or your family buy green agricultural products online? (Online shopping frequency, variety, quantity and total value, etc.) (3) how satisfied are you with online shopping of the green agricultural products? If satisfied, from what aspects? If you are not satisfied, please list the specific reasons. (4) Which of the following factors will be your or your family considerations in the willingness to consume green agricultural products online shopping? (There are 46 specific options, are selected in the relevant literature appearing the quality of service evaluation index system) (5) What do you think consumers are willing to buy green agricultural products through online shopping? Please list more than three.

The open questionnaire was issued by 8 classes in the third year of marketing, business administration, trade economics and e-commerce in Nanjing University of Finance and Economics. A total of 335 questionnaires were distributed and 323 copies were collected. After the removal of invalid questionnaires (mainly students and their families do not have the experience of green agricultural products online shopping, to ensure the sample selection targeted), a total of 169 effective questionnaires were collected, the effective questionnaires rate is $50.5 \%$. Then, we summarize service quality evaluation items of shopping green agricultural products online collected by the open questionnaire, combine the interviews with more than 30 postgraduates of marketing specialty, and screen out 24 entries to design service evaluation system of online shopping of green agricultural products. The quality evaluation index system is divided into six dimensions (Table I). For details in it, the tangible property refers to the tangible display part of the shopping website of green agricultural products such as the attractiveness of the website design and the rationality of the web structure, the reliability is the extent to which the shopping site of green agricultural products can accurately complete its commitment to the service, the responsiveness means the shopping site of green agricultural products can at any time provide consumers with fast and effective service, the guarantee is the degree to the shopping site of green agricultural products can provide relevant services to meet consumer demand, the empathy refers to the awareness and ability from the consumer demand point of view, the innovation means the shopping site of green agricultural products can offer super value service without expectation.

TABLE I. EVALUATION INDEX SYSTEM OF SERVICE QUALITY OF ONLINE SHOPPING FOR GREEN AGRICULTURAL PRODUCTS

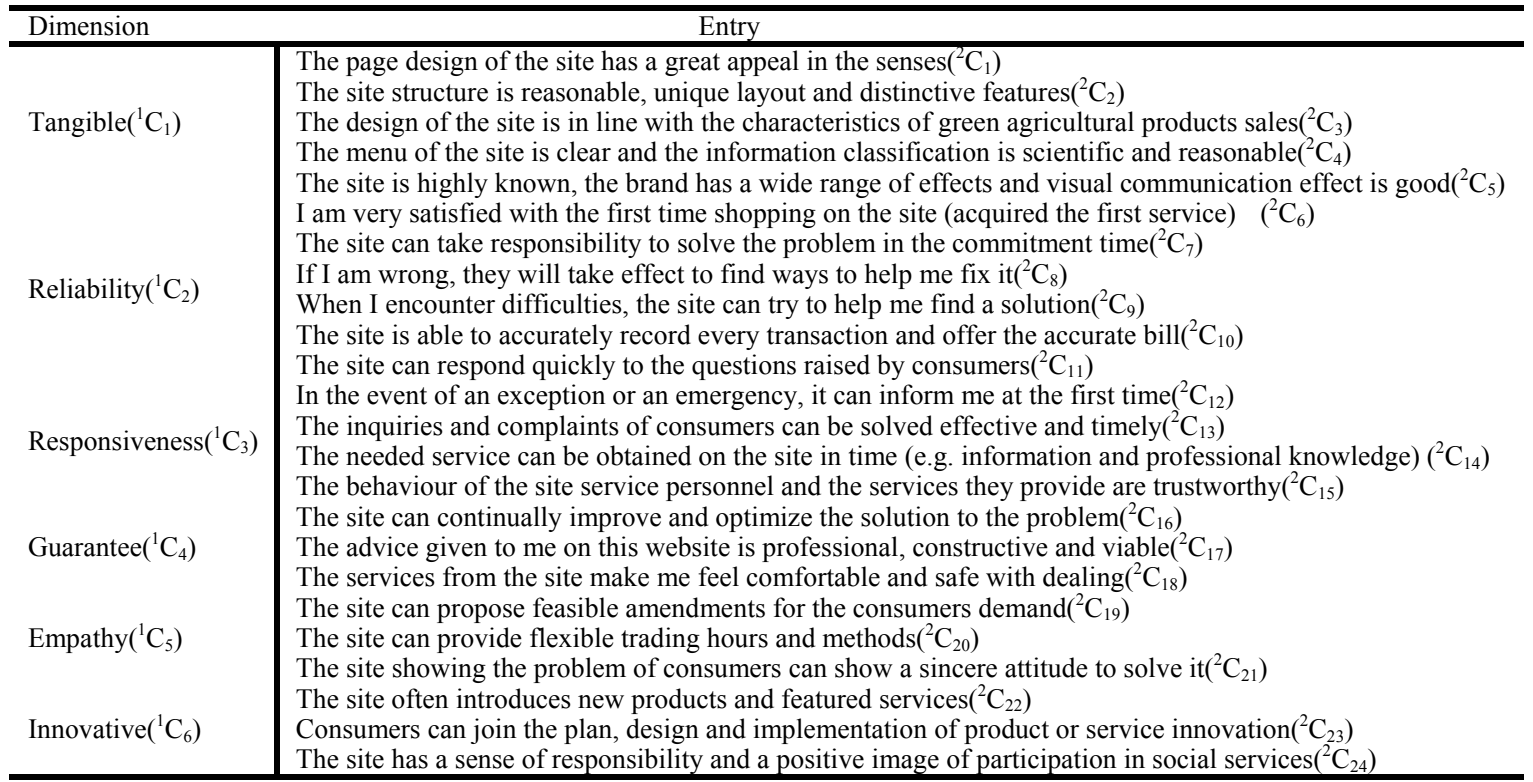




\section{B. The Determination of the Fuzzy Number of the Language Variable Value}

Considering the uncertainty of the decision maker and the decision object, we use the fuzzy number and fuzzy language variables to express the weight of each item and its metrics of the relevant dimensions in the case of multiplayer decision, and use sing fuzzy number and non-fuzzy number to obtain the performance index and relative weight. "Triangular fuzzy number" and "linguistic variable" are the two main concepts of evaluating the language variable preference level, which embodies the "importance" and "satisfaction", namely the decision makers adopt the weight set $\mathrm{W}=$ \{very low, low, High, and very high $\}$ to evaluate the relative importance of the various criteria, use the language grade set $\mathrm{S}=$ \{very poor, poor, medium, good, excellent $\}$ to evaluate the satisfaction of different criteria. The membership function of the weight set $\mathrm{W}$ and the language level set $\mathrm{S}$ is represented by the appropriate triangular fuzzy number, as shown in Table II.

TABLE II. MEMBERSHIP FUNCTION OF LANGUAGE VARIABLE VALUE

\begin{tabular}{ll}
\hline Language Variable Value & Fuzzy Number \\
\hline very low (very poor) & $(0,0,0.25)$ \\
low (poor) & $(0,0.25,0.5)$ \\
medium (middle) & $(0.25,0.5,0.75)$ \\
high (good) & $(0.5,0.75,1)$ \\
very high (excellent) & $(0.75,1,1)$ \\
\hline
\end{tabular}

\section{The Integration Method of Dimension Fuzzy Weight}

Suppose that decision makers $\left(\mathrm{D}_{1}, \mathrm{D}_{2}, \ldots, \mathrm{D}_{\mathrm{n}}\right)$ evaluate the service quality of online shopping of green agricultural products under each $\mathrm{k}$ dimensions $\left({ }^{\mathrm{h}} \mathrm{C}_{\mathrm{t}}, \mathrm{t}=1,2, \ldots, \mathrm{k}, \mathrm{h}=1,2\right.$; where 1 is the dimension, 2 is the entry).

Using the eigenvector method, the decision makers obtain the binary comparison judgment matrix of the dimension. We make the normalization of the elements in the matrix, and get the decision maker's evaluation of the importance of each dimension.

In order to reflect the integration of multiple expert opinions and take into account the uncertainties of decision making, this paper uses the fuzzy Delphi method to express the integration results of each expert opinion with fuzzy numbers. Compared with the method of determining the weight of traditional analytic hierarchy process, we can use the triangular fuzzy number to integrate the decision maker's evaluation of each dimension; the triangular fuzzy number weighting method is as followed:

$$
{ }^{1} W_{t}=\left(e_{t}, f_{t}, g_{t}\right)
$$

In the formula: ${ }^{1} W_{t}$ is the fuzzy weight of the dimension, $e_{t}=\min _{j}\left\{{ }^{1} W_{j t}\right\}, \quad g_{t}=\max _{j}\left\{{ }^{1} W_{j t}\right\}, \quad f_{t}=\left(\prod_{j=1}^{n}{ }^{1} W_{j t}\right)^{1 / n} \quad, \quad{ }^{1} W_{j t}$ is the importance evaluation of decision maker $\mathrm{j}$ to dimension $\mathrm{t}$

\section{The Weight of the Entry and the Fuzzy Satisfaction of the Dimension}

To reflect the uncertainties of the decision object and facilitate the integration of the experts opinions, the importance of the entries and the satisfaction of the service quality are expressed by the fuzzy language variables shown in Table II, respectively, and integrate the evaluation of the decision maker of the average operator. Thus, let $\oplus$ and $\otimes$ represent the fuzzy addition and multiplication operators, respectively, the integration method of average fuzzy satisfaction and entry weight for online shopping service quality is as followed:

$$
\begin{aligned}
S_{t} & =\left(\frac{1}{n}\right) \otimes\left(S_{t 1} \oplus S_{t 2} \oplus \cdots \oplus S_{t n}\right) \\
{ }^{2} W_{t} & =\left(\frac{1}{n}\right) \otimes\left({ }^{2} W_{t 1} \oplus^{2} W_{t 2} \oplus \cdots \oplus^{2} W_{t n}\right),
\end{aligned}
$$

In the formula:

$\mathrm{S}_{\mathrm{t}}$ - Average Fuzzy Satisfaction Based on Entry ${ }^{2} C_{t}$

${ }^{2} W_{t}$ - The average weight of entry ${ }^{2} C_{t}$

$S_{t j}$-Decision maker $\mathrm{D}_{\mathrm{j}}$ assigns the rank under item ${ }^{2} C_{t}$

${ }^{2} W_{t j}$ - The weight assignment of decision maker $D_{j}$ to entry ${ }^{2} C_{t}$.

In this way, the fuzzy satisfaction $\mathrm{R}$ of each dimension can be obtained by integrating $S_{t}$ and ${ }^{2} W_{t}$.

$$
R=\left(\frac{1}{k}\right) \otimes\left[\left(S_{1} \otimes^{2} W_{1}\right) \oplus\left(S_{2} \otimes^{2} W_{2}\right) \oplus \cdot \oplus\left(S_{k} \otimes^{2} W_{k}\right)\right]
$$

Let $S_{t j}=\left(q_{t j}, o_{t j}, p_{t j}\right)$ and ${ }^{2} W_{t j}=\left(c_{t j}, a_{t j}, b_{t j}\right)$ be triangular fuzzy numbers. Then $\mathrm{R}$ can be expressed as approximately:

$R \cong(Y, Q, Z)$

In the formula:

$$
\begin{aligned}
& Y=\sum_{t=1}^{k} q_{t} c_{t} / k, Q=\sum_{t=1}^{k} o_{t} a_{t} / k, \quad Z=\sum_{t=1}^{k} p_{t} b_{t} / k, \quad q_{t}=\sum_{j=1}^{n} a_{t j} / n, \\
& o_{t}=\sum_{j=1}^{n} o_{t j} / n, \\
& P_{t}=\sum_{j=1}^{n} p_{t j} / n, C_{t}=\sum_{j=1}^{n} C_{i j} / n \quad a_{t}=\sum_{j=1}^{n} a_{i j} / n \quad b_{t}=\sum_{j=1}^{n} b_{j j} / n, \\
& t=1,2, \cdots, k ; j=1,2, \cdots, n .
\end{aligned}
$$




\section{E. Fuzzy Comprehensive Score of Online Purchase Quality of Green Agricultural Products}

After obtaining the fuzzy satisfaction degree $\mathrm{R}$ of each dimension and the weight value of each dimension, we can get the fuzzy comprehensive score of online shopping service quality:

$$
F=R \otimes{ }^{1} W_{t} \cong\left(Y^{\prime}, Q^{\prime}, Z^{\prime}\right),
$$

In the formula, $Y^{\prime}=Y \times e_{t}, Q^{\prime}=Q \times f_{t}, Z^{\prime}=Z \times g_{t}$.

After getting a fuzzy comprehensive score $F$, Using the average method, we can get the final real score of network service quality

$$
A(F)=\frac{1}{3}\left(Y^{\prime}+Q^{\prime}+Z^{\prime}\right)
$$

\section{F. Evaluation Steps of Online Shopping Service Quality of} Green Agricultural Products based on Fuzzy Analytic Hierarchy Process

Specific steps are as followed:

The first step: evaluation of green agricultural products online shopping service quality evaluation system weight of each dimension: using fuzzy Delphi method to determine the fuzzy number of weights of each dimension.

The second step: establish the relevant level of the language variable

1) Select the appropriate preference level for the weight of all entries;

2) Select the satisfaction level for the item-based quality of service.

The third step: integration of Fuzzy "Satisfaction” Index

1) Integrate the weight of the entry; get the integration weight $2 \mathrm{Wt}$;
2) Integrate the views of all decision makers, form an integrated fuzzy level St based on all entries $2 \mathrm{Ct}$;

3) Integrate St and $2 \mathrm{Wt}$, get the fuzzy "satisfaction" index $\mathrm{R}$ for each dimension.

The fourth step: the calculation of the fuzzy overall evaluation

Integrate the weight sets $1 \mathrm{Wt}$ and fuzzy "satisfaction" index $\mathrm{R}$ of the dimension, get the fuzzy overall score $\mathrm{F}$ of online shopping service quality.

The fifth step: the calculation of the final real evaluation

The fuzzy holistic evaluation $\mathrm{F}$ is transformed into the real score A $(F)$ by the mean method.

\section{The Application of OnLine Shopping SeRVice Quality EVAluation of Agricultural PRODUCTS}

We invited the relevant management staff working in the Jingdong Mall customer service center, to apply the above system of quality evaluation of online purchase of green agricultural products by Fuzzy Satisfaction Score and Weight Determination. The specific analysis process is as followed:

Step 1: We invite the five experts (D1, D2, D3, D4, and D5) of the relevant departments of Nanjing University and Nanjing Agricultural College forming a committee to determine the quality of online shopping service. The evaluation index system is shown in Table I.

Step 2: Table III shows that the decision makers obtain the judgment matrix of the two pairs of the criteria according to the eigenvector method. Table IV shows the elements in the matrix normalized by columns and the evaluation of the importance of each criterion by the decision maker.

TABLE III. THE DECISION MAKER'S TWO - PAIR COMPARISON MATRIX

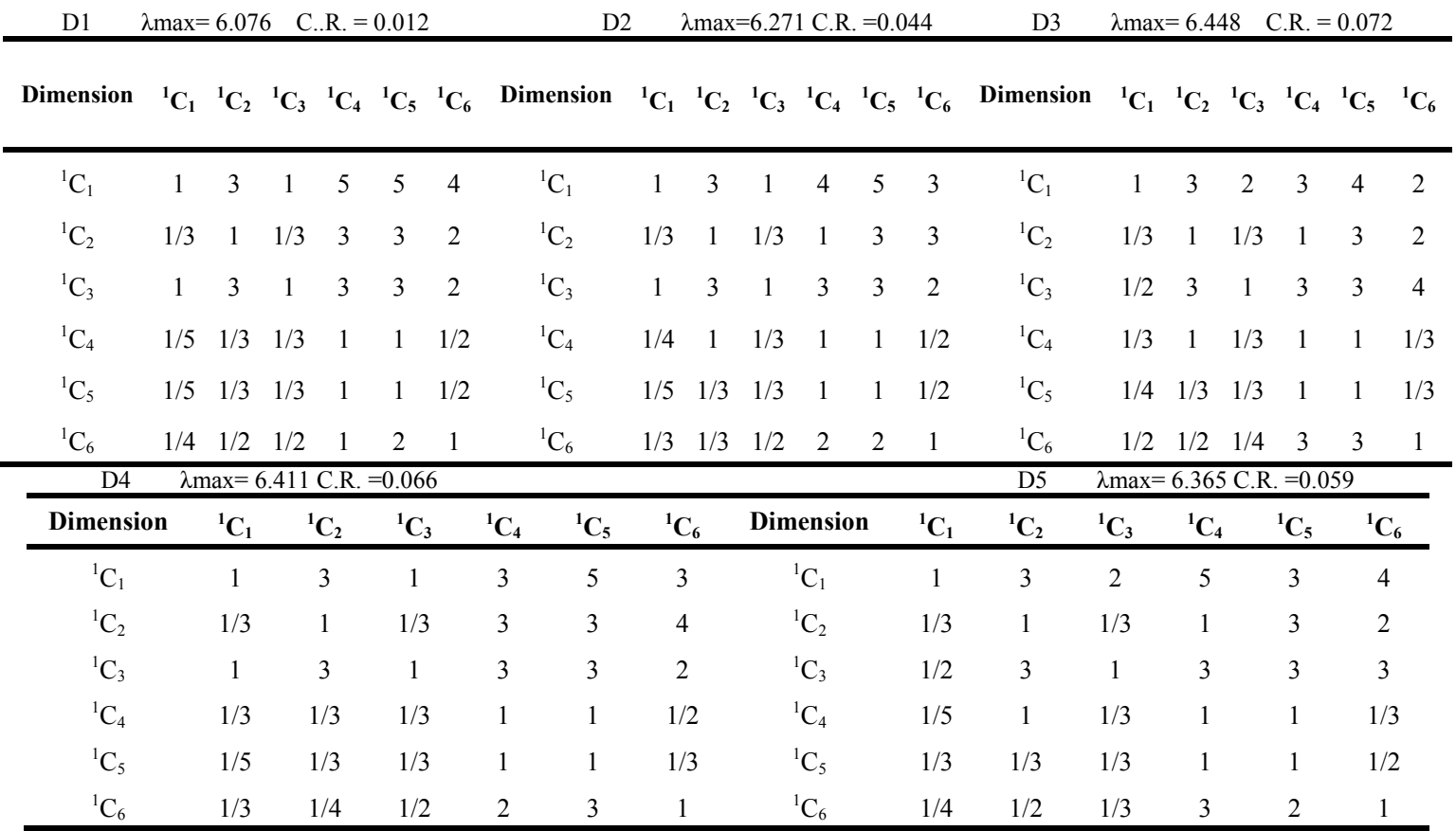


TABLE IV. DECISION MAKERS EVALUATE THE IMPORTANCE OF EACH DIMENSION

\begin{tabular}{cccccc}
\hline Decision makers & $\mathrm{D} 1$ & $\mathrm{D} 2$ & $\mathrm{D} 3$ & $\mathrm{D} 4$ & $\mathrm{D} 5$ \\
\hline Norm & 0.1536 & 0.1387 & 0.1314 & 0.1745 & 0.1282 \\
${ }^{1} \mathrm{C}_{2}$ & 0.2661 & 0.2885 & 0.2733 & 0.2693 & 0.2541 \\
${ }^{1} \mathrm{C}_{3}$ & 0.0647 & 0.0817 & 0.0812 & 0.0713 & 0.0727 \\
${ }^{1} \mathrm{C}_{4}$ & 0.0647 & 0.0655 & 0.0644 & 0.0612 & 0.0705 \\
${ }^{1} \mathrm{C}_{5}$ & 0.0968 & 0.0962 & 0.1277 & 0.1100 & 0.1088 \\
\hline${ }^{1} \mathrm{C}_{6}$ & &
\end{tabular}

In this paper, we use the triangular fuzzy number to integrate decision makers' evaluation of each dimension, and then make use of the geometric mean to obtain the fuzzy weight, at last apply the formula (1) to integrate the fuzzy weights of different criteria, which can be seen in Table $\mathbf{V}$ for details.

Step 3: The decision maker uses the fuzzy numbers of the language variable values in Table II to evaluate the weight ${ }^{2} W_{t j}$ and satisfaction $\mathrm{S}_{\mathrm{tj}}$ of the entries.

Step 4: Using the average operator to Integrate decision makers' comments. Using the formula (2) - (5), the fuzzy satisfaction index $\mathrm{R}$ for each dimension can be obtained, see Table VI.
Step 5: From the formula (6), the fuzzy overall evaluation of the quality of online shopping service of green agricultural products can be obtained, $\mathrm{F}=(0.3642,0.7813$, and 1.0541).

Step 6: From the formula (7) to obtain the final real evaluation of the quality of online shopping service of green agricultural products, $\mathrm{A}(\mathrm{F})=0.7332$.

The results of the applied example show that service quality evaluation level of green agricultural products online shopping in Jingdong Mall belongs to the upper reaches of the level, which is basically consistent with the relevant evaluation results of Jingdong Mall service quality.

TABLE V. THE IMPORTANCE OF DIMENSION

\begin{tabular}{cc}
\hline Norm & Weights \\
\hline${ }^{1} \mathrm{C}_{1}$ & ${ }^{1} \mathrm{~W}_{1}=(0.3138,0.3364,0.3657)$ \\
${ }^{1} \mathrm{C}_{2}$ & ${ }^{1} \mathrm{~W}_{2}=(0.1282,0.1443,0.1745)$ \\
${ }^{1} \mathrm{C}_{3}$ & ${ }^{1} \mathrm{~W}_{3}=(0.2541, .02700,0.2885)$ \\
${ }^{1} \mathrm{C}_{4}$ & ${ }^{1} \mathrm{~W}_{4}=(0.0647,0.0740,0.0817)$ \\
${ }^{1} \mathrm{C}_{5}$ & ${ }^{1} \mathrm{~W}_{5}=(0.0612,0.0652,0.0705)$ \\
& ${ }^{1} \mathrm{C}_{6}=(0.0962,0.1073,0.1277)$ \\
\hline
\end{tabular}

TABLE VI. FUZZY SATISFACTION INDEX OF DIMENSION (R)

\begin{tabular}{cc}
\hline Norm & Fuzzy Satisfaction \\
\hline${ }^{1} \mathrm{C}_{1}$ & $(0.4156,0.8000,0.9506)$ \\
${ }^{1} \mathrm{C}_{2}$ & $(0.3688,0.7344,0.9256)$ \\
${ }^{1} \mathrm{C}_{3}$ & $(0.3756,0.7444,0.9500)$ \\
${ }^{1} \mathrm{C}_{4}$ & $(0.4044,0.7856,0.9500)$ \\
${ }^{1} \mathrm{C}_{5}$ & $(0.4550,0.8550,1.0000)$ \\
${ }^{1} \mathrm{C}_{6}$ & $(0.3856,0.8507,0.9608)$ \\
\hline
\end{tabular}

\section{CONCLUSION AND REVELATION}

\section{A. Improving Online Shopping Service Quality of Green Agricultural Products Should Look at Consumers' Satisfaction}

We should first pay attention to the physical display of green agricultural products online shopping service content, incorporate the service content into the entire operating process, increase appeal on the senses and highlight the characteristics of green agricultural products and website service quality level in the design; Secondly, make full use of the internet with a public intermediary channels, maintain a positive communication and exchange with consumers, to achieve the service quality and customer demand for dynamic matching; Thirdly, as the IWOM has greatly increased the effectiveness and persuasiveness of communication in terms of the amount of information, the degree of dispersion, the richness of sources, etc. , the IWOM gradually become the main channel for consumers searching products, services and brand information.

\section{B. Improving Online Shopping Service Quality of Green \\ Agricultural Products Should be guaranteed by \\ Technological Innovation}

Increasing investment is demanded to create a network media platform, e-commerce platform, mobile application 
platform, safety agricultural certification traceability system, etc. Furthermore, actively carrying out technological innovation, business model innovation and product and service content innovation, to provide network providers with the most advanced and applicable business philosophy and technology platform regarding to the green agricultural products. And constantly improve the level of professional services to promote the service quality of green agricultural products online shopping.

\section{Improving Online Shopping Service Quality of Green Agricultural Products should be powered by Service Innovation}

In fact, the proposed green agricultural products online shopping service quality evaluation system of 24 entries are closely related to service innovation and examined by the test of empirical research. Therefore, the innovative service concept proposed truly reflects the customer-first mindset, helping us optimize the service process, jumping out of the misunderstanding that "the customer has no opinion means satisfaction" and contributing to the theory of service quality management.

\section{REFERENCES}

[1] Alam S S, Yasin N M. What factors influence online brand trust [J]. Journal of theoretical and applied electronic commerce research, 2010, 5(3): 78-89.

[2] ZHAO P,LUO Y. Case analysis of agricultural E-commerce [J]. Journal of business economics,2011(7):19-23. (In Chinese)

[3] LIANG W Z,HOU Y X,GE R. The analysis of online shopping for agricultural products [J]. Issues in agricultural economy,2012(4):40-43. (In Chinese)

[4] CHE Y. Problems and countermeasures of Chinese agricultural products network marketing [J]. Hubei province agricultural science, 2012(20): 38-40. (In Chinese) 